\title{
The Telling of Things: Imagining with, through and about Machines.
}

\author{
Tobias Revell \& Kristina Andersen
}

\begin{abstract}
'A machine is a thing. It is on the object side of things. Yet a machine is an anomalous kind of thing, an object that seems to exceed its objecthood in certain ways, through its quality of being automatic... Machines do not work for us, and so a machine is always a kind of substitute for a subject.' (Connor, 2017, p.50)
\end{abstract}

Machines are as much imagined as they are technical propositions. Several authors, not least Giles Deleuze have noted that 'machines are social before being technical' (Deleuze, 1988, p.39) and as social objects machines are bound up in the social imaginaries we create for, through, with and about them.

The nexus of the imaginary, the technical and the non-human have always been complicated and ever-shifting, riddled with apparent paradoxes. James C. Scott, David Graeber and others have written extensively on the way that machines reproduce humancentric reductionism; attempting to reduce and simulate natural phenomenon to technical processes and then reinscribing these simulations on the non-machine world. (Graeber, 2016; Scott, 1998) Conversely, many others show how machines create reflexive opportunities to reconsider the relationship of the human and non-human through almost transcendental machine experiences. (Pohflepp, 2016; Levitt, 2018) We imagine them to be simple tools of 'innovation,' testament to human skills of exploiting natural phenomenon (Singleton, 2014) while simultaneously being rhetorical partners and meaning makers. (Losh, 2016; Hayles 2019).

These complexities demand a novel perspective on humans, non-humans and machines which we aim to explore here. However, in seeking to briefly describe some relationships with imaginary machines and how we imagine our relationships with machines and how machines shape our imaginations and how machines imagine us and how we mechanise imagination, we will eschew the never-ending project of rationalising complexity into technical categories. Instead we turn to the Argentinian surrealist author Jorge Luis Borges, who, in his his own satire of the absurdity of formal classification wrote (or, claimed to have discovered) the Celestial Emporium of Benevolent Knowledge, a non-western categorisation system for animals:

In its remote pages it is written that the animals are divided into: (a) belonging to the emperor, (b) embalmed, (c) tame, (d) sucking pigs, (e) sirens, (f) fabulous, (g) stray 
dogs, (h) included in the present classification, (i) frenzied, (j) innumerable, (k) drawn with a very fine camelhair brus $h$, (l) et cetera, $(m)$ having just broken the water pitcher, (n) that from a long way off look like flies. (Borges, 1952)

Our brief review takes these categories as a starting point for problemetising and poeticising positions and differences so that we might easier demystify or dispel the assumed prehistoric relationship of humans, machines and imagination and see them in novel ways. Each categoris ation may be used as short-hand for particular forms of relationship in future work. This essay as a whole functions as a thing to think with.

\section{Belonging to the Emperor}

\section{Where the emancipatory and imaginative potential of machines is foreclosed to service entrenched power dynamics.}

Throughout the 20th century, the machine was conceptualised as a thing of power. The Italian Futurists wrote their manifesto inspired by the superhuman potential of the machinic man (invariably a man). Kitschy product demonstrations of kitchen gadgets and cars laud consumerist tropes; speed, power and efficiency of production and consumption. These are the driving priorities of 'innovation'. While - tragically - the word 'technology,' once translatable as 'knowledge of techniques' has become synonymous with the nebulous worlds of gizmology and gadgetry bringing with it a reverence of obfuscated power, secret knowledge, access and socially-constructed notions of 'progress'. Things of Belonging to the Emperor might be described as the resting state of machines and imagination in the majority of the western-originating cannon. They are unchallenging, uncritical and the nexus of imagination, humans and machines tend to fit comfortably together in this category.

Belonging to the Emperors are usually bound up in the imagination of individuality and superhero-like qualities enabled by technology that might enable super-human achievement or status. When describing the emotional attraction of superheros, the cartoonist Chris Ware says: 'When we are weak we wanted to be strong, and when we were very weak we wanted to be very strong.' (Ware, 2001) We can maybe extend such desires to the imagination of the powerful or magical machine. We tell stories of machines that provide the protagonist (and by extension us) with unequalled powers, an unfair advantage. The dream of the unfair advantage drives the imagination of Belonging to the Emperormachines, real and imagined.

\section{Embalmed}

Where machines are purely imaginary. There may be physical attempts, representations or prototypes of them but their functioning is purely imaginary.

We need look no further than the television or cinema to see the world of imaginary machines in high resolution. The main-streaming of science fiction in the 1990s and the 
new-found popularity of speculative fiction such as Black Mirror has put discussion of the imaginary machine at the forefront of pop culture discussion of future technological innovation. For example, the recursive relations hip between science fiction and innovation is apparent in technology media headlines comparing new gadgets to things previously only found in films: 'SF [S cience fiction] plays an important role in the shaping of desire for change, for progress, for novelty, for a sense of wonder and of discovery' (Bassett, S teinmueller, \& Voss, 2013) Think here of every headline comparing a new device or software to something from Steven S pielberg's Minority Report or the apparent foresight of Spike Jonze's Herin describing the relationship we might have with Amazon's Alexa or Apple's Siri.

Embalmed things in cinema, television and pop culture often embody foreclosed social aspirations of power and control (see Belonging to the Emperor) but can often act as warning tales of potential technologies or even suggest new social imaginaries through imaginary machines (s ee Frenzieds). Additionally, Embalmed can be apocryphal or charlatan in nature as machines that claim to serve some imaginary technical function but in fact do not. Here 'the production of apocryphal technologies is fueled by desires and fantasies that can never be realized' such as mind reading or control, prediction or divination. (Enns, 2019, p.1) The lineage of charlatan or apocryphal technologies is long and storied; from the claimed healing properties of the 'animal magnetis $\mathrm{m}$ ' of Franz Anton Mesmer to bogus radiation detectors sold after the Fukushima disaster. The continued resonance of fantastic imaginary technologies is clearly a notable and relevant branch of the machine imaginary.

More pressingly, it is arguable that the imaginary function of machines are as important as their technical function. So while Embalmed might often fail to live up to their technical claims they occupy prominent positions in individual, scientific and social imagination making them charis matic figures in the development of new machines and imaginaries.

\section{Tame}

Where machines are imagined to be nothing more than tools, devoid of any inherent politics or social entanglement in their construction or use.

Not much needs to be said on this category as nothing can be categorised here.

\section{Suckling pigs}

Where the non-machine world is read as, reduced and rendered as machinic components or processes by humans.

Machines are 'constructed things' and as such are reducible to their parts. This reductionis $m$ has a tendency to pervade our worldview as it makes so much sense when dealing with the technological framework of daily social activity. Stephen Connor suggests 
that all human activities are 'a matter of techne, technique, or technes is' and so are 'imagined mechanically.' (Connor, 2017, p.188) In other words, because all human activities are inherently technical, humans are incapable of imagining the world in a non-machinic way; without classifying it, trying to reduce it to components and parts.

As Connor suggests, we can only imagine the world mechanically. Think, for example, of the reduction of the 'natural world' to a human-imposed order; the naming of species and their classification, the reduction of ecologies to machine-like systems of trees and matrices. This tendency of projecting a mechanical 'truth' onto nature through understanding how systems are 'supposed' to work is legible in everything from city planning to cybernetics to surveillance.

Anthropologist James C. Scott describes how this machinic imagining of the natural and social world drives the powerful to physically impress their machinic imaginings back onto the world:

The utopian, immanent, and continually frustrated goal of the modern state is to reduce the chaotic, disorderly, constantly changing social reality beneath it to something more closely resembling the adminis trative grid of its observations. (S cott, 1998, p. 82)

Scott's work particularly focuses on agriculture and forestry describing this 'utopian' project of reductionism in three stages: Firstly that the world or field of action (the forest, the farm, the city and so on) is observed and measured, extracting key data points and variables with which to work with. Secondly, these data points and variables are abstractly modelled, whether in a spreads heet database, a 'smart' system or a simulation in order to optimise this 'machine' version of reality for the desired outcome. Finally, once a successful model or simulation is devised the world is remodelled to suit it. With the easy accessibility of cheaper sensors and surveillance architectures, more of the world is reshaped to fit the optimal design of a piece of software: Airports, shopping centres, factories and distribution centres are essentially physicalised software - material representations of the way machines imagine the world where 'data' (goods, planes, humans and so on) are processed through them. (Kitchin \& Dodge, 2011) These and other Suckling Pigs are non-machine spaces for humans, designed according to a human imagination of machinic worlds that prioritise command and control in search of machinic efficiency.

\section{Sirens}

Where the human world is rendered to prioritise legibility for machines.

Automated farms, shipping container ports, airports, pit mines and other software-driven landscapes are edge cases of human and software worlds. These are spaces in which humans and machines move together and as such they bear semblances of legibility and 
navigability to both. (Young, 2019) However, increasingly the world is built in such a way that it is still perceptible to humans but illegible to them. To draw an example that is parallel with James C. Scott's work on industrial forests replanted to prioritise yield for human consumption - a Suckling Pig, we are already beginning to see forests replanted to prioritise elctro-magnetic propagation. (Manaugh, 2019) These forests, based on science showing the electro-magnetic permeability of different species and ideal arrangement and heights, service a physical phenomenon imperceptible to humans and which we can only imagine through the way it instantiates in the physical world.

There are easier examples of human-made worlds for machines: A library of books has a system for both humans and machines to be able to navigate it: The Dewey decimal system allows machines to quickly reference and retrieve items using a system that carries little inherent meaning for most humans without reference to the index. Meanwhile the alphabetical and subject-based organisation will allow most humans to find their way to their desired item by act of cross-referencing.

By comparison, Amazon's warehouses or 'fulfilment centres' are almost completely automated and are organised randomly; the most efficient means of rapid storage and retrieval for a machine. (Baraniuk, 2015) Here, new goods come in the front and are stored in no particular order. The database managing the warehouse can identify the precise location of each object by a mix of GPS and bar codes but there is no human 'sense' to the order. The imagination at play is completely that of the database. The organisation and distribution of objects in these spaces follows the machinic logics and so can often appear possessed by an 'other' intelligence.

\section{Fabulous}

\section{Where machines exhibit sublime properties that fuel human imagination.}

An often untapped power of machines lies in their ability to broaden the social, spiritual and cultural potential of those who interact with them, with their enchantment of the individual or the society with new possibilities. Anthropologist Alfred Gell describes how mastery of tools and technologies 'enchant' society, projecting power but also a quasi-spiritual and sublime appreciation of non-human artifice. (Gell, 1992) In new artificial intelligence technologies such as machine learning, we find ourselves marvelling at machines again as they appear to exceed humans with 'processes that are congenitally alien to us-those that are too vast, too distributed or too transtemporal.' (Pohflepp, 2016, p.10)

There is a sublime Lovecraftian sense presented in the contemporary situation in which 'a computer learns and consequently builds its own representation of a classification decision, it does so without regard for human comprehension.' (Burrell, 2016, p.10) Unlike Stray Dogs this is less because the functioning of the machine is technically obfuscated, forcing us to imagine causality (see also Having just broke the water pitchen) but because the very being of a machine itself exceeds human perceptibility. This in turn extends and fuels our own 
imagination of things previously unimaginable. Deborah Levitt encourages us to use this imaginative opportunity to engage the new technical affordances of new machines of simulation and creativity to dissolve the regime of representation and reality best embodied by Suckling pigs. (Levitt, 2018, p.121).

Here we find a great opportunity for 'art.' Projects like Jimmy Loizeau and James Auger's Ripple Counter - part of their 'Sublime Gadgets' series (Auger \& Loizeau, 2012) - explore alternative ways that machines might be with us. In this project a floating device simply counts ripple moving across the water's surface. Nearby a counter with twenty-four digits ticks over towards a septillion, a number that will never be reached. The series uses a playful humour and larger-than-human perspective to playfully draws on philosopher Joseph Addison's notions of the 'Pleasures of The Imagination' in an attempt to denormalise technologies and explore how they might go beyond or outside the human, revealing to us new perspectives in the sublime. The Slow Inevitable Death of American Muscle by Jonathan Schipper shows us a car crash in excruciating slow motion, teasing the audience with the juxtaposition of power and speed embodied in the powerful American muscle car machines and the imperceptible slowness of the crash spectacle happening over days or even weeks, de-spectaclising the trope of the car, the car crash and the explosive speed of machines. Finally the works of Ryoji lkeda draws the human into a Lovecraftian tale of the profound otherness of the titanic oceans of data produced and disseminated by automated systems. Flashes, explosions, roars of light and sound sweep across enormous spaces without care for human interpretation or presense.

As opposed to Embalmed, Fabulous do not claim to perform utilitarian technical functions and exist purely to extend the spiritual and aesthetic experience of being human in the presence of machines. These Fabulous works and many others like them bring the human under the auspice of the machinic phylum without regard for human ambition, use or purpose and most often beyond the perception of the human senses into the pure otherness of machines.

\section{Stray Dogs}

Where humans may struggle to imagine causality or technical function in/of a machine due to their inscrutability. This may give it the appearance of exceeding machine-ness. (aka Wild Machines)

In his book How are Things? A Philosophical Experiment, (Droit, 2003) Roger-Pol Droit describes being overwhelmed by things, by 'folded propositions. Or the folds of ancient and vanished phrases. Or the solid residue of extinct words' (Droit, 2003, p.11). He asks himself 'How are things?' and answers the question himself as an informed imagination:

'The freezer is a machine of secrets. It belongs to the family of thing-enigmas, which perplex us and which we approach with hesitation: the sense of a surface, of volume of a door, of an interior which can be accessed. All of which tells us next to nothing. 
Things of this kind are self-enclosed, keeping their counsel. Boxes containing mysteries. We become used to them, we draw our own conclusions, but we never really discover how they work.' (Droit, 2003, p.115)

Stephen Connor put forward the notion that imagination and machines are inextricably linked because machines seem to exceed their object-ness. They can perform tasks and actions that exceed expectations and thus create new imaginary potentials. Maelzel's Chess Player, alternately called the 'Automaton', or the 'Mechanical Turk' was an apparently autonomous chess playing machine constructed by Wolfgang von Kempelen in 1770 which was toured around the courts of Europe for almost fifty years by Johann Nepomuk Mälzel, a Bavarian musician. The machine was an astounding technical marvel, able to beat human opponents such as Maria Theresa and Napoleon I with one commentator describing how 'no exhibition of the kind has ever elicited so general attention as the Chess-Player of Maelzel.' (Poe, 1836) This reviewer, Edgar Allen Poe - like others suspected the machine to be a trick but nonetheless commented that the Chess Player was so astounding a machine precisely because it behaved in a non-machine-like way:

'[A machine's] movements, however complex, are never imagined to be otherwise than finite and determinate. But the case is widely different with the Chess-Player. With him there is no determinate progression. No one move in chess necessarily follows upon any one other.' (Poe, 1836)

The non-machine-ness of the $C$ hess Player fuelled the public imagination precisely because it exceeded the definition of machine. Consequently dozens of explanations arose for its functioning, some being closer to correct; that the mechanism cleverly concealed a human player directing the machine's movements, and some bordering on the supernatural; that it was haunted by the ghost of a Prussian mercenary. Reports of inscrutable Stray Dogs exist in the European canon as far back as 807 when the court of Charlemagne received the gift of a mechanical clock from the caliph of Baghdad and continued to fascinate the European world with notions of 'old-world magic' for a thousand years. (Truitt, n.d.) However, the Mechanical Turk bears particular weight over the imagination of machines. This is evidenced by the contemporary Amazon's Mechanical Turk Stray Dog. Here, the inscrutable machine (Amazon) disguises (without apparent irony) a technical functioning that is in fact exploitative human labour.

\section{Included in this present categorisation}

Extending from the machinery that produces pasta, plastic buckets, statistics and sound, we find that we consider most things 'machines'. The machine-nes of eating, thinking, and paying attention is directly related to a vague notion of systems. One adds something, and another something is returned. One follows a procedure and a procedure is returned. An action is performed or imagined and something is returned. It is this rhythm of doing and being done that allows the 'Included in this present categorisation' category to expand. The category is only defined by its boundary: that which was not included. 
The world-as-transactional-machine lets us see the material differently, or rather thinking like a machine makes us look at a field of flax and thinking of fabric, thread, (and muesli). The machine might work by turning a material into another. The flax is ultimately turned into linen and we will look at it and think of thread counts, patterns and moments of use. In this way the machine has turned a field of grass into a material ready for our use and mis use, and it is this turning of material that gives such a machine its identity and power. By turning a material into something else we engage in the machine magic of material transformations.

\section{Frenzied}

Where machines propagate new imaginaries.

* This may be read as a oppositional categorisation to Things Belonging to The Emperor in the sense that Frenzied necessarily challenges status-quo imaginaries and acts against imaginary foreclosure. Further research is needed to study machines or imaginings that may cross both categories, perhaps necessitating a new category.

Machines also come with imaginable futures attached to them; from Gutenberg's Press and the Protestant revolutions to the car and the 20th century version of freedom. Machines are entangled and drawn up in the social imagination of what our world is and what we want from it. At the individual level, the latest gadget or gizmo comes not with a technical specification but a set of promises and visions of what life will be like once one holds it, put it in one's pocket and use it.

These become most revealed in deviant edge cases, where machines serve new purposes or are adapted. Here we find the site of Jugaad innovation; the reclaiming of machines for new purposes as well as hacking, exploitation and deviant misuse. In the video game subculture of speedrunning for example the game is read as a digital architecture through which new games can be created using glitches and inconsistencies in the design to deceive the developers' intended purposes. This playful approach to the machines of the game relies on a canny understanding of its affordances and limitations only discovered through experimentation. More sinisterly, the use of the burgeoning Internet of Things ecosystem as a base from which to launch DDoS and ransomware attacks has shown how the technical attributes of machines will always allow for those who wish to exploit them.

The Frenzied machine buzzes with the promise and potential of itself, but it is a broken promise, reminiscent of the broken promise of the souvenir, that promises a connection that it cannot deliver (Stewart 1993). The Frenzied machine is frantically insistent on continuing this non-delivery, as a culturally complex DoS attack, ready to be subverted to the purposes of art and harassment.

\section{Innumerable}

Those machines and imaganings we have forgotten. 
Alfred Gell describes technology as made of three things: The sum of the 'artefacts which are employed as tools... the knowledge which makes possible the invention, making and use of tools [and] the networks of social relationships which... provide the necessary conditions' for their use. (Gell, 1988, p.6) In other words a machine is dependent on its discrete existence, the knowledge of its use and the social necessity of its use. Innumerable are the machines that have fallen out of knowledge, necessity or existence and become forgotten. Certainly too many to recount here.

\section{Drawn with a very fine camelhair brush}

Where machines render imagined things.

Equally, machines shape how we imagine. The growth of computer generated image technology and attendant platforms like virtual, augmented, extended and mixed reality have allowed us to visualise and share imagination in new ways. Here we find the dreams of simulation and holography, the 'Holodeck' of Star Trek and the Deep Fake. These machines imagine worlds for the human senses. However, in doing so they shape those worlds in accordance with their software predispositions. As Alan Warburton points out: 'Computer scientists incrementally created a library of simulated phenomena [and] software companies packaged these tools together into multi-purpose 3D animation programs. These creative suites naturally prioritise certain tasks and outputs. They ship with presets for lights, objects, motions, bodies and materials.' (Warburton, 2019)

The machines used to construct visions of the future whether concept products, renderings of future developments, science-fiction cinema or data visualisation increasingly rely on standardised software packages with standardised templates. As a consequence, imagination of the world and the future becomes limited and predescribed, homogenised by the software used to envision it. As Joel McKim suggests: 'memory is becoming increasingly homogenized through both the conditioning or standardization of usergenerated material and the perpetual re-circulation of a relatively small (and increasingly commercial, rather than amateur) pool of available content.' (McKim, 2017, p. 291)

The power of Drawn with a very fine camelhair brush is in the excellence and fidelity of their production of imagination: The advances in real-time photorealism, facial recognition, machine vision and deep learning that have enabled more and more granular simulation of natural phenomena. As a consequence, they can be used for disinformation or exploitation: 'Computational propaganda has become a normal part of the digital public sphere...These techniques will also continue to evolve as new technologies ... are poised to fundamentally reshape society and politics.' (Stubbs, 2019) Recent elections have seen the proliferation of doctored video and deep fakes to sway political opinion, often drawing on and confirming what a viewer already imagines to be true. 


\title{
Et cetera
}

All the things not included in the Included in this present categorisation ' category. Also known as 'the rest'.

Taken out of any sensible or coherent context, a well worn Whitehead quote reads: ' $A$ traveller who has lost his way should not ask where am I, what he wants to know is, where are the other places.' (Whitehead) Et cetera are these other places. In a world of machines, we may find ourselves looking for the not-machines, that which is left-over or material not yet constructed into machines. We may consider Et cetera the category for material in what Annie Albers would call its original form: unconstructed and unprocessed (Albers, 1937).

\section{Having just broken the water pitcher}

\author{
Where previously unimagined machines or uses of machines may emerge serendipitously. \\ Maybe.
}

While imagining future technologies through the notions of machine-ness might be strongly influenced by what we already imagine to be possible (see Belonging to the Emperor), sometimes machines defy our imagination. Here, they can become alternately alienating or inspiring. We are shocked and displaced when machines behave in ways we could not previously imagine. Popular media is replete with stories of technology behaving in new or unexpected ways, whether by design or accident. With an increasing amount of 'smart' things in the world, we are increasingly facing unexpected surprises in how we imagine our life with these things to be. The story of the smart lock that would occasionally not lock due to a bug (Brown, 2014) or Amazon Echos laughing maniacally on their own (ITV, 2018) indicate a world of perceived autonomy beyond our imagination.

These happenings often drive us to imagine supernatural explanations for machines that are already presented as somewhat magical. Further to this, the black boxing of these technologies in their complexity and legal and technical abstraction forces us to dig for primal explanations of their functioning and glitching. (Revell \& Kane, n.d.) William Stahl in Venerating the Black Box draws on the similarities in the narratives of power around technology and the occult that lead to $36 \%$ of TIME magazine articles about the PC referring to it and its creators in terms of the occult. In his work he demonstrates how magic and technology are entwined in the pursuit of power with the resulting superhero fantasies that pervade the media reporting on machines.

This magical attribution falls on an apparent lack of perceptible causality in the operation of machines and their inscrutability (see Stray Dogs). In our need to imagine the functioning of these machines we will often create new imaginaries or ideas that propagate ad infinitum to create new machines and imaginations. Apophenia, or the tendency to connect unrelated things in the imagination can, in fact lead to imagination. Hito Steyerl writes that 'apophenia happens when narrative breaks down and causality has to be recognized — or invented- 
across a cacophony of spam, spin, fake, and gadget chatter.' (Steyerl, 2018, p.5) Here, apophenia results in invention; creating new, previously unimaginable meanings through accident as when the messy outcome of an over-trained neural network 'reveals its hardwired ideologies and preferences.' (S teyerl, 2018, p.10)

\section{That from a long way off look like flies}

Where machines become props, tools or partners in imagining new worlds.

The relationship between the machine and the imaginary is recursive. For example, the car enables us to imagine the flying car, the electric car, the autonomous car and others. In this way. new machines are prefigured by the imagination of the previous machines. Without the first car, the autonomous car would have been unimaginable. Broadly speaking we imagine new machines with the machines we have and the machines we have define the things we imagine. To misquote and paraphrase; we imagine our machines, thereafter, they imagine us.

As opposed to Embalmed that are only even imaginary in existence or function, That from a long way off look like flies cross the imaginary/real divide. They are speculations and distant proposals for new machines and imaginations. They promise new futures and better worlds. One might find an iPad and consider its similarity to the devices proposed in 2001: A Space Odyssey or the marvel at how the countdown clock of Fritz Lang's Woman on the Moon became a central motif of space flight. These machines usher in nascent realities as portals on the edge of the imagination and reality.

From here, That from a long way off look like flies might progress into other categories, passing out of reality and into the purely imaginary as Embalmed. Or they might find serendipitous use as having just broken the water pitcher. Or exceed human perception as Fabulous.

We have tried to describe a world of imagined and actual machines. The machine-ness of our surroundings is both a description of the fascination and horror with that which we do not understand or are barred from touching, and an extension of a perception of everyday life as procedural and sometimes barely functional. We approach each machine with a whispered curse or plea: please work, please don't harm me, please respond. We are deeply emotionally bound to the success of these encounters, we modify what we want to what the machine can do, and we cover for its errors. Entire careers are given over to the cleaning up of the mess from the machines.

The absurdity of categorising the entangled worlds of humans and machines and their coimaginative potential should by now be absolutely apparent. Humans are technopolitical beings and construct machines into their social imagination. In attempting to categorise them we draw attention to a paradox that would have pleased Borges: No matter how absurd the categorisation we are providing proof of its validity by reflexively imagining with 
machines in the mere acts of researching, recalling, writing, editing, talking about and reading this very chapter.

\section{References}

Baraniuk, C. (2015). How Algorithms run Amazon's Warehouses. BBC Future. Available at: http://www.bbc.com/future/story/20150818-how-algorithms-run-amazons-warehouses (Accessed 25th September 2019)

Bassett C., Steinmueller E., Voss G., (2013) Better Made Up: The Mutual Influence of Science fiction and Innovation, Nesta working paper

Brown, J. (2014). Review: August Smart Lock. Wired [Online] Available at: https://www.wired.com/2014/10/august-smart-lock-review/ (Accessed 23rd September 2019).

Borges, J. L. (1952). The Analytical Language of John Wilkins. [Online[ Available at: https://ccrma.stanford.edu/courses/155/assignment/ex1/Borges.pdf (Accessed 19 April 2020)

Burrell, J. (2016). How the machine 'thinks': Understanding opacity in machine learning algorithms. Big Data and Society. 3(1) pp.1-12

Connor, S. (2017). Dream Machines. London: Open Humanities Press.

Daston, L. \& Galison, P. (2010). Objectivity. MIT: Zone Books.

Deleuze, G. (1988) Foucault. Minneapolis: University of Minnesota Press

Enns, A., (2019) Apocryphal Psychotechnologies. In. Allen, J. \& Enns, A. (Eds.). Continent. 8(1-2). [Online] Available at: http://continentcontinent.cc/index.php/continent (Accessed 16th April 2020)

Gell, A. (1992). The Technology of Enchantment and the Enchantment of Technology. In: Anthropology, Art and Aesthetics. Oxford: Clarendon, pp. 40-66.

Gell, A. (1988). Technology and Magic. Anthropology Today, April 4(2), pp. 6-9.

Graeber, D. (2015). The Utopia of Rules: On Technology, Stupidity and the Secret Joys of Beureaucracy. Brooklyn: Melville House.

Hayles, N. K., (2019). Can Computers Create Meanings? A Cyber/Bio/Semiotic Perspective. Critical Inquiry 46(1), pp. 32-55.

ITV. (2018) Amazon Alexa users spooked by creepy 'laugh' emitted by their devices seemingly at random. ITV News. [Online] Available at: http://www.itv.com/news/2018-0308/amazon-alexa-users-spooked-by-creepy-laugh-emitted-by-their-devices-seemingly-atrandom/ (Accessed 25th September 2019) 
Kitchin, R., Dodge, M. (2011). Code/Space: Software and Everyday Life. Cambridge, Massachusetts: MIT Press

Latour, B. (2000). Pandora's Hope: Essays on The Reality of Science Studies. Cambridge, Massachus sets: Harvard University Press.

Levitt, D., (2018). The Animatic Apparatus; Animation, Vitality and the Futures of the Image. Alresford, Hampshire: Zero Books

Losh, E. (2016). Sensing Exigence; A R hetoric For S mart Objects. Computational Culture $1(5)$.

Manaugh, G., (2019). Computational Landscape Architecture, BLDGBLOG [Online] Available at: http://www.bldgblog.com/2019/02/computational-landscape-architecture/ (Accessed 19th April 2020)

McKim, J. (2017). S peculative Animation: Digital Projections of Urban Past and Future. Animation: An Interdisciplinary Journal 12(3). pp.287-305

Merriam-Webster, n.d. "Machine". Merriam-Webster's Dictionary [Online] Available at: https://www.merriam-webs ter.com/dictionary/machine (Accessed 25th September 2019).

Poe, E. A. (1836). Maelzel's Chess-Player. Southern Literary Messenger, Volume 2, pp. 318326.

Pohflepp, S. (2016). Pattern Agnosia and the Image not made by Human Hand.

Droit, R-P. (2003). How Are Things? A Philosophical Experiment, Translated from Dernières nouvelles des choses. Faber and Faber

Scott, J. C. (1998). Seeing Like A State: How Certain Schemes to Improve The Human Condition Have Failed. New Haven, Connecticut: Yale University Press.

Singleton, B. (2014). On craft and being crafty: Human behaviour as the object of design. PhD thesis. University of Northumbria, Newcastle.

Stahl, W. A. (1995). Venerating the Black Box: Magic in Media Discourse on Technology. Science, Technology, \& Human Values, 20(2), pp. 234-258.

Steyerl, H., (2018). A Sea of Data: Pattern Recognition and Corporate Animism (Forked Version). In. Bachman, G., Beyes, T., Bunz, M., \& Chun, W. H. K., (Eds.) Pattern Discrimination. Minneapolis: University of Minnesota Press, pp. 1-22.

Stubbs, J. (2019). Viral visuals driving social media manipulation on YouTube, Instagram: researchers. Reuters. [Online] Available at: https://www.reuters.com/article/us-facebookdisinformation/viral-visuals-driving-social-media-manipulation-on-youtube-instagramresearchers-idUSKBN1WB0ED (Accessed 29 September 2019) 
Truitt, E. R., (n.d.) Preternatural machines, Aeon [Online] Available at:

https://aeon.co/essays/medieval-technology-indis tinguis hable-from-magic (Accessed 19th April 2020)

Warburton, A., (2019). Fairytales of Motion [Video] Available at:

https://vimeo.com/343626951 (Accessed 30 April 2020)

Ware, C., (2001). Superpowers. This American Life. [Podcat] Available at:

https://www.thisamericanlife.org/178/superpowers (Accessed 30 April 2020)

Young, L., (2019). Machine Landscapes; Architecture of the Post-Anthropocene.

Chichester: John Wiley \& Sons. 